\title{
Repeated Exposure to Rapidly Developing Hypoxemia Influences the Interaction between Oxygen and Carbon Dioxide in Initiating Arousal from Sleep in Lambs
}

\author{
JAMES E. FEWELL AND GANESH G. KONDURI
}

Perinatal Research Laboratory, Department of Pediatrics, University of Arkansas for Medical Sciences, Little Rock, Arkansas 72205 and Reproductive Medicine Research Group, Department of Obstetrics and Gynaecology and Medical Physiology, University of Calgary, Health Sciences Centre, Calgary, Alberta T2N 4N1, Canada

\begin{abstract}
Experiments were done on 12 lambs to determine if repeated exposure to hypoxemia influences the interaction between oxygen and carbon dioxide in causing arousal response from sleep. Each lamb was anesthetized and instrumented for sleep staging and measurements of arterial Hb oxygen saturation. No sooner than 3 days after surgery, measurements were made in quiet and active sleep during control periods when the lambs were breathing $21 \%$ oxygen and during experimental periods when the lambs were breathing either $5 \% \mathrm{O}_{2}-\mathbf{0} \% \mathrm{CO}_{2}, 5 \% \mathrm{O}_{2}-5 \% \mathrm{CO}_{2}$ or $5 \% \mathrm{O}_{2}-10 \% \mathrm{CO}_{2}$. Each experimental period was terminated during each epoch by changing the inspired gas mixture back to $21 \%$ oxygen once the animal aroused from sleep. The lambs were divided into two groups. One group $(n=7)$ was studied without prior exposure to hypoxemia and the other group $(n=5)$ was studied after exposure to $5 \%$ oxygen during $\sim 100$ epochs of sleep until they aroused. In lambs not previously exposed to hypoxemia, there was evidence for a slight interaction between oxygen and carbon dioxide in initiating arousal but only from quiet sleep. Repeated exposure to hypoxemia resulted in an arousal response decrement to hypoxemia. In lambs previously exposed to hypoxemia, there was evidence for an interaction between oxygen and carbon dioxide in initiating arousal from both quiet and active sleep (i.e. the time to arousal decreased and the saturation at arousal increased as increasing amounts of carbon dioxide were added to the hypoxic gas mixture). Thus, our data provide evidence that a greater interaction exists between oxygen and carbon dioxide in initiating arousal-particularly in active sleeponce an arousal response decrement has developed to hypoxemia alone. (Pediatr Res 24: 28-33, 1988)
\end{abstract}

\section{Abbreviation}

ALTE, apparent life-threatening event

Arousal is an important protective response that may prevent severe hypoxemia and death during sleep. Hypoxemia may occur

Received December 18, 1987; accepted February 25, 1988.

Correspondence and request for reprints James E. Fewell, Ph.D., Department of Obstetrics and Gynaecology and Medical Physiology, University of Calgary, Health Sciences Centre, 3330 Hospital Drive, N.W., Calgary, Alberta T2N 4N1, Canada.

Supported by United Stated Public Health Service Grants HL34377 and HD24018 and the Alberta Heritage Foundation for Medical Research. J.E.F. is an Established Investigator of the American Heart Association and a Heritage Medical Scholar of the Alberta Heritage Foundation for Medical Research. during sleep in individuals with chronic lung disease (1-3) and/ or during central or obstructive apnea. The usual respiratory response to hypoxemia is an increase in ventilation which tends to increase the alveolar and arterial oxygen tension. However, inasmuch as the ventilatory response to hypoxemia is decreased during active sleep compared to quiet sleep in lambs (4) and calves (5) (i.e. two species that develop rib cage collapse paradox during active sleep) and the resumption of tidal ventilation during obstructive apnea is usually preceded by arousal (6-9), the arousal response may be the most important response to hypoxemia during sleep. In newborn humans, Stark and Thach (10) found that arousal affected the pattern of restoration of air flow during upper airway obstruction produced by neck flexion. In the absence of arousal, reopening of the airway was delayed and incomplete. In contrast, when arousal did occur, reopening of the airway was immediate and complete.

Despite the apparent importance of the arousal response from sleep to respiratory stimuli, little information is available in newborns concerning the arousal response per se, the mechanism of the arousal response or of factors that may impair the arousal response to respiratory stimuli. The purpose of our experiments was to investigate whether repeated exposure to rapidly developing hypoxemia would influence the interaction between oxygen and carbon dioxide in causing arousal from sleep in lambs.

\section{METHODS}

Twelve lambs ranging in age from 10 to 19 days were studied. Each lamb was separated from its ewe 1 to 3 days after birth and was housed in our laboratory in a plexiglas cage with continuous access to milk (Lamb Milk Replacer, Land O'Lakes, Inc., Fort Dodge, IA). The lambs were among other lambs, fed and slept ad libitum, and soon became accustomed to the surroundings and laboratory personnel.

Surgical preparation. Each lamb underwent one operation before study. For surgery, each lamb was given atropine sulfate $(0.2 \mathrm{mg} / \mathrm{kg}$ subcutaneously) and ketamine $\mathrm{HCl}(10 \mathrm{mg} / \mathrm{kg}$ intramuscularly) and their trachea was intubated with a cuffed endotracheal tube. The cuff was inflated to a gas tight fit and anesthesia was maintained by ventilating the lamb's lungs with 1 to $3 \%$ isofluorane (Forane) in oxygen and nitrous oxide $(3: 1)$. An electrocardiogram and rectal temperature were monitored during surgery; body temperature was kept as near $39^{\circ} \mathrm{C}$ as possible with a heating pad.

The operation was done between 7 and 16 days of age. A double-lumen fiberoptic catheter oximeter (model U440 Opticath, Oximetrix, Inc., Mountain View, CA; $90 \%$ response to a step change in arterial $\mathrm{Hb}$ oxygen saturation within $5 \mathrm{~s}$ ) was 
inserted to the thoracic aorta via a femoral artery for continuous measurement of $\mathrm{Hb}$ oxygen saturation and blood pressure. Electrodes for the following recordings were also implanted: electrocorticogram, electrooculogram, nuchal electromyogram, and diaphragm electromyogram. A reference wire was sutured into the subcutaneous tissue of the scalp. The electrodes were made in our laboratory and were paired, Teflon-coated, multistranded stainless steel wires (AS 633, Cooner Wire Co., Chatsworth, CA); approximately $3 \mathrm{~mm}$ of the tip of each was bared for implantation. The proximal end of each wire was bared and soldered to the appropriate pin of an 18 pin electrical plug which was interfaced with four differential high impedance probes (7HIP5G, Grass Medical Instruments, Quincy, MA) during a study.

A tracheotomy was also performed and a fenestrated tracheostomy tube (Shiley, Inc., Irvine, CA) placed in the trachea (11). After surgery, the decannulation cannula was inserted into the tracheostomy tube so that airflow during tidal respiration would be through the upper airway. The lambs were allowed to recover from surgery in a Shor-Line intensive care unit for small animals (Schroer Manufacturing Company, Kansas City, MO) and were then placed in a plexiglas study cage in our sleep laboratory but were not studied before the 3rd postoperative day. The lambs received antibiotics (procaine penicillin $\mathrm{G} 100,000 \mathrm{U} / \mathrm{kg}$; gentamicin sulfate $2 \mathrm{mg} / \mathrm{kg}$ ) for 5 days beginning on the day of surgery.

Conditions of observations. Our sleep laboratory consists of a large room $(12 \times 26 \mathrm{ft})$ which contains two sound attenuating chambers (W $4 \mathrm{ft}, \mathrm{H} 6.5 \mathrm{ft}, \mathrm{L} 6.5 \mathrm{ft}$ ). Each chamber has a oneway viewing mirror as well as a closed circuit video system to observe the lambs. Temperature, sound, and lighting can be precisely controlled in each chamber. Before a study, a partition is placed in the cage to prevent the lamb from turning around once the catheter and electrode are connected. However, the lamb can still lie down, stand up, and feed ad libitum.

For a study, the vascular catheter is connected to a strain gauge manometer (Gould P23ID, Gould, Inc., Oxnard, CA) using rigid pressure monitoring tubing and the optical connector is connected to the optical module of the oximeter processor; the strain gauge manometer is placed at the approximate level of the heart when the animal is lying down. The inner cannula is placed into the tracheostomy tube and a breathing circuit (Neonatal Ventilator Circuit, model 5302, Intec Medical Inc., Blue Springs, MO) attached so that 10 liters per minute of a known gas (i.e. $5 \% \mathrm{O}_{2}-$ $0 \% \mathrm{CO}_{2}, 5 \% \mathrm{O}_{2}-5 \% \mathrm{CO}_{2}, 5 \% \mathrm{O}_{2}-10 \% \mathrm{CO}_{2}$ ) can be passed by the tracheostomy tube. The tip of a small catheter is placed through the T-piece of the breathing circuit into the tracheostomy tube so that respired gases can be measured (Beckman OM-11 and LB-2 analyzers; Advanced Technology Laboratories, Anaheim, CA). The 18-pin electrical plug is connected to the differential high impedance probes; a heavy duty cable connects the differential high impedance probes to A.C. preamplifiers (model 7P5 wide band A.C. EEG pre-amplifier, Grass Medical Instruments, Quincy, MA) in the adjacent room. The electrophysiological signals are high-pass filtered using the $1 / 2$ amplitude low frequency response control on the A.C. preamplifiers (electrocorticogram $1.0 \mathrm{~Hz}$, electrooculogram $0.3 \mathrm{~Hz}$, and electromyogram $3 \mathrm{~Hz}$ ). The amplified activity from the electrocorticogram is full-wave rectified and then integrated (model 7P10 Polygraph Integrator, Grass Medical Instruments) to give a running record of the total accumulated area under the electrocortical waves (12).

The following electrophysiological criteria were used to define behavioral state once the animal was lying down (12). During quiet wakefulness, the electrocorticogram shows a fast wave-low voltage pattern; there are occasional eye movements and there is tonic activity on the nuchal electromyogram. During quiet sleep, the electrocorticogram shows a slow wave-high voltage pattern; there are no eye movements and there is tonic activity on the nuchal electromyogram. During active sleep, the electrocorticogram shows a fast wave-low voltage pattern; there are rapid eye movements on the electrooculogram; there is no activity on the nuchal electromyogram; and there are occasional fast ear, facial, and limb twitches. Each lamb was allowed to cycle through at least one epoch of quiet sleep before the experiment actually began so that we could determine the amplitude of the integrated electrocortical activity and set strict criteria for defining quiet sleep.

The following electrophysiological criteria were used to define arousal from sleep (12). During quiet sleep, the point of arousal was determined by a change in the electrocorticogram from a high voltage-slow wave pattern to a low voltage-fast wave pattern (Fig. 1). During active sleep, the point of arousal was determined by a return of tonic activity on the nuchal electromyogram.

Experimental protocol. During a study, systemic arterial blood pressure, $\mathrm{Hb}$ oxygen saturation, and the electrophysiological signals were recorded on a Grass model 7 polygraph (Grass Medical Instruments) and the lambs were monitored on a closedcircuit video system. Measurements were made during 30-s control periods when the lambs were breathing $21 \%$ oxygen and during experimental periods when the lambs were breathing either $5 \% \mathrm{O}_{2}-0 \% \mathrm{CO}_{2}, 5 \% \mathrm{O}_{2}-5 \% \mathrm{CO}_{2}$, or $5 \% \mathrm{O}_{2}-10 \% \mathrm{CO}_{2}$. At least two epochs of quiet sleep and active sleep were collected on each gas mixture in each animal. Hypoxemia was terminated during an experimental period by changing the inspired oxygen concentration to $21 \%$ once the animal aroused from sleep. The gas mixture used during the experimental period was alternated on an hourly basis to avoid any sequence effects and the sequence was changed between animals (e.g. animal $15 \% \mathrm{O}_{2}-0 \% \mathrm{CO}_{2}$, $5 \% \mathrm{O}_{2}-5 \% \mathrm{CO}_{2}, 5 \% \mathrm{O}_{2}-10 \% \quad \mathrm{CO}_{2}$, etc.; animal $25 \% \quad \mathrm{O}_{2}-5 \%$ $\mathrm{CO}_{2}, 5 \% \mathrm{O}_{2}-0 \% \mathrm{CO}_{2}, 5 \% \mathrm{O}_{2}-10 \% \mathrm{CO}_{2}$, etc.; animal $35 \% \mathrm{O}_{2}-$ $10 \% \mathrm{CO}_{2}, 5 \% \mathrm{O}_{2}-0 \% \mathrm{CO}_{2}, 5 \% \mathrm{O}_{2}-5 \% \mathrm{CO}_{2}$, etc.; etc.). Because the mean epoch lengths of quiet sleep and active sleep of chronically instrumented lambs during this age range are 6 to $7 \mathrm{~min}$ and 3 to $4 \mathrm{~min}$, respectively (Johnson $\mathrm{P}$, unpublished data), control measurements were made approximately 2 to $3 \mathrm{~min}$ after the lamb entered quiet sleep and approximately $30 \mathrm{~s}$ after the lamb entered active sleep.

The lambs were divided into two groups. Group N (normoxemia, $n=7$ ) was studied without prior exposure to rapidly developing (hypoxemia (i.e. $5 \% \quad \mathrm{O}_{2}-0 \% \quad \mathrm{CO}_{2}$ ) and group $\mathbf{H}$ (hypoxemia, $n=5$ ) was studied after repeated exposure to rapidly developing (hypoxemia during approximately 100 epochs of sleep ( 24 to $48 \mathrm{~h}$ ) until they aroused.

Statistical analysis. For every animal, we determined an average value for each variable during the control period and during the experimental period immediately preceding arousal (arterial $\mathrm{Hb}$ oxygen saturation, heart rate, and blood pressure-five cardiac cycles; respiratory frequency and integrated diaphragm activityfive respiratory cycles if possible) for quiet sleep and active sleep; these values were used for statistical analysis. To analyze the data statistically, we performed a three-factor analysis of variance for repeated measures of the same variable to determine if group (normoxemia versus hypoxemia), gas mixture $\left(5 \% \mathrm{O}_{2}-0 \% \mathrm{CO}_{2}\right.$, $5 \% \mathrm{O}_{2}-5 \% \mathrm{CO}_{2}, 5 \% \mathrm{O}_{2}-10 \% \mathrm{CO}_{2}$ ) or period (control versus experimental) affected arterial $\mathrm{Hb}$ oxygen saturation, blood pressure, heart rate or respiratory rate (13). A two-factor analysis of variance for repeated measures of the same variable was done to determine if group or gas affected the time to arousal or the percent change in diaphragm activity (13). If there were significant differences, a Duncan's multiple range test was done to determine which means were statistically different at the 0.05 level of significance (14).

\section{RESULTS}

In lambs not previously exposed to rapidly developing hypoxemia (i.e. group $\mathrm{N}$ ), there was evidence for a slight interaction between oxygen and carbon dioxide in initiating arousal, but only in quiet sleep. (Fig. 2). The time to arousal was decreased and the saturation at arousal was increased when the lambs 


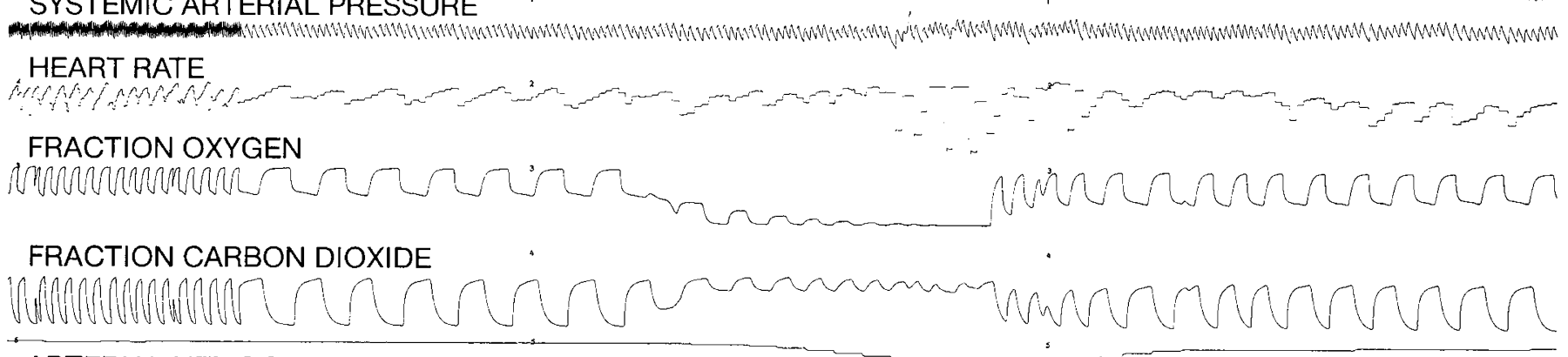

ARTERIAL HEMOGLOBIN OXYGEN SATURATION

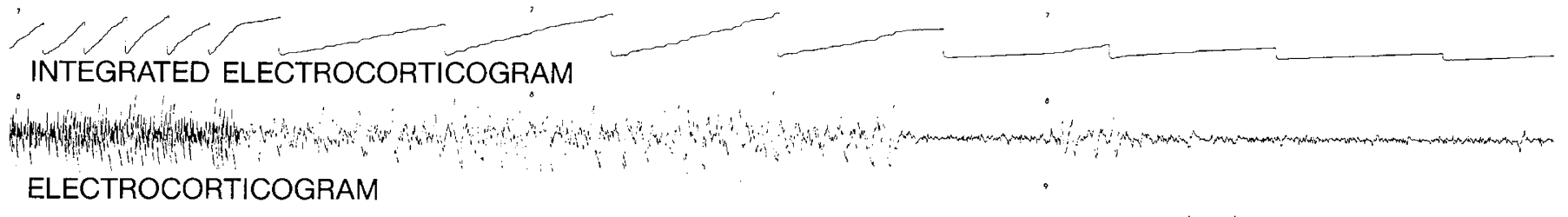

ELECTRO-OCULOGRAM

NUCHAL ELECTROMYOGRAM

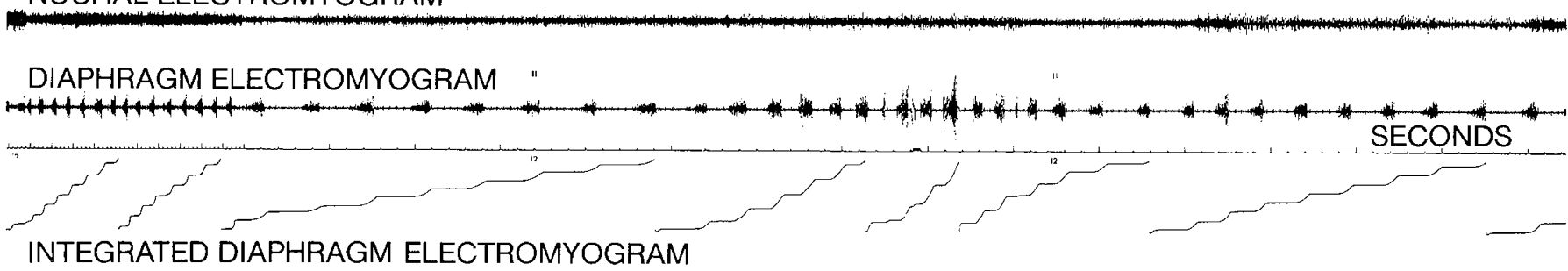

Fig. 1. Tracing showing physiological variables during inhalation of $5 \%$ oxygen and $5 \%$ carbon dioxide in quiet sleep. Note change in electrocorticogram with arousal.

breathed $5 \% \mathrm{O}_{2}-10 \% \mathrm{CO}_{2}$ during the experimental period compared to $5 \% \mathrm{O}_{2}-0 \% \mathrm{CO}_{2}$.

Repeated exposure to rapidly developing hypoxemia did influence the arousal response in both quiet and active sleep (Fig. 2). The arousal response from sleep tended to adapt (i.e. increased time to arousal and decreased saturation at arousal; compare 5\% $\mathrm{O}_{2}-0 \% \mathrm{CO}_{2}$ group $\mathrm{N}$ versus group $\mathrm{H}$ ) after repeated exposure to rapidly developing hypoxemia.

In lambs previously exposed to rapidly developing hypoxemia (i.e. group $\mathrm{H}$ ), there was evidence for an interaction between oxygen and carbon dioxide in initiating arousal from quiet sleep and active sleep (Fig. 2). The time to arousal decreased, and the saturation at arousal increased, as increasing amounts of carbon dioxide were added to the hypoxic gas mixture.

Blood pressure-both systolic and diastolic-tended to increase during rapidly developing hypoxemia before arousal in both groups of lambs (Table 1); this response was most consistent in active sleep. The increase in systolic pressure before arousal was greatest in group $\mathrm{H}$ when the lambs breathed $5 \% \mathrm{O}_{2}-0 \%$ $\mathrm{CO}_{2}$; this increase was attenuated as increasing amounts of carbon dioxide were added to the inspired gas mixture. There were few statistically significant changes in heart rate before arousal during rapidly developing hypoxemia (Table 2). However, there was a tendency for heart rate to increase before arousal in quiet sleep, whereas heart rate tended to decrease before arousal in active sleep.

Respiratory frequency increased during rapidly developing hypoxemia before arousal in all lambs (Table 3). During quiet sleep, the increase in respiratory frequency was accentuated in group $\mathrm{H}$ compared to group $\mathrm{N}$ when the lambs inspired $5 \% \mathrm{O}_{2-}$ $0 \% \mathrm{CO}_{2}$ or $5 \% \mathrm{O}_{2}-5 \% \quad \mathrm{CO}_{2}$. Diaphragm electromyographic activity increased during rapidly developing hypoxemia (Table 4). During active sleep, the increase in diaphragm electromyo- graphic activity was accentuated as increasing amounts of carbon dioxide were added to the inspired gas mixture.

\section{DISCUSSION}

Our study provides new information about the arousal response from sleep to rapidly developing hypoxemia in lambs. Specifically, repeated exposure to rapidly developing hypoxemia influences the interaction between oxygen and carbon dioxide in causing arousal, particularly in active sleep.

In lambs not previously exposed to rapidly developing hypoxemia, there was evidence for a slight interaction between oxygen and carbon dioxide in initiating arousal in quiet sleep. These results are similar to those of Phillipson et al. (15) who provided evidence for an interaction between oxygen and carbon dioxide in initiating arousal from quiet sleep but not active sleep in adult dogs.

The mechanism(s) responsible for initiating arousal from sleep during hypoxemia and during hypercapnia in young lambs is not known. It is possible that similar mechanisms, such as stimulation of peripheral chemoreceptors directly or stimulation of lung receptors indirectly by an increase in ventilation, initiate the arousal response. The time to arousal during inhalation of $5 \%$ oxygen (quiet sleep $18 \pm 7 \mathrm{~s}$, active sleep $44 \pm 21 \mathrm{~s}$, group $\mathrm{N}$ present study) and during inhalation of $10 \%$ carbon dioxide [quiet sleep $21 \pm 10 \mathrm{~s}$, active sleep $58 \pm 17 \mathrm{~s}(16)$ ] are similar in both sleep states. Furthermore, the increase in respiratory rate before arousal during inhalation of $5 \%$ oxygen (quiet sleep $30 \pm$ 8 to $42 \pm 11$, active sleep $36 \pm 6$ to $50 \pm 3$ ) and during inhalation of $10 \%$ carbon dioxide [quiet sleep $27 \pm 4$ to $45 \pm 14$, active sleep $34 \pm 7$ to $46 \pm 11$ (16)] are similar. It is also possible that dissimilar mechanisms, such as stimulation of central chemoreceptors or an increase in blood pressure (17), initiate arousal 

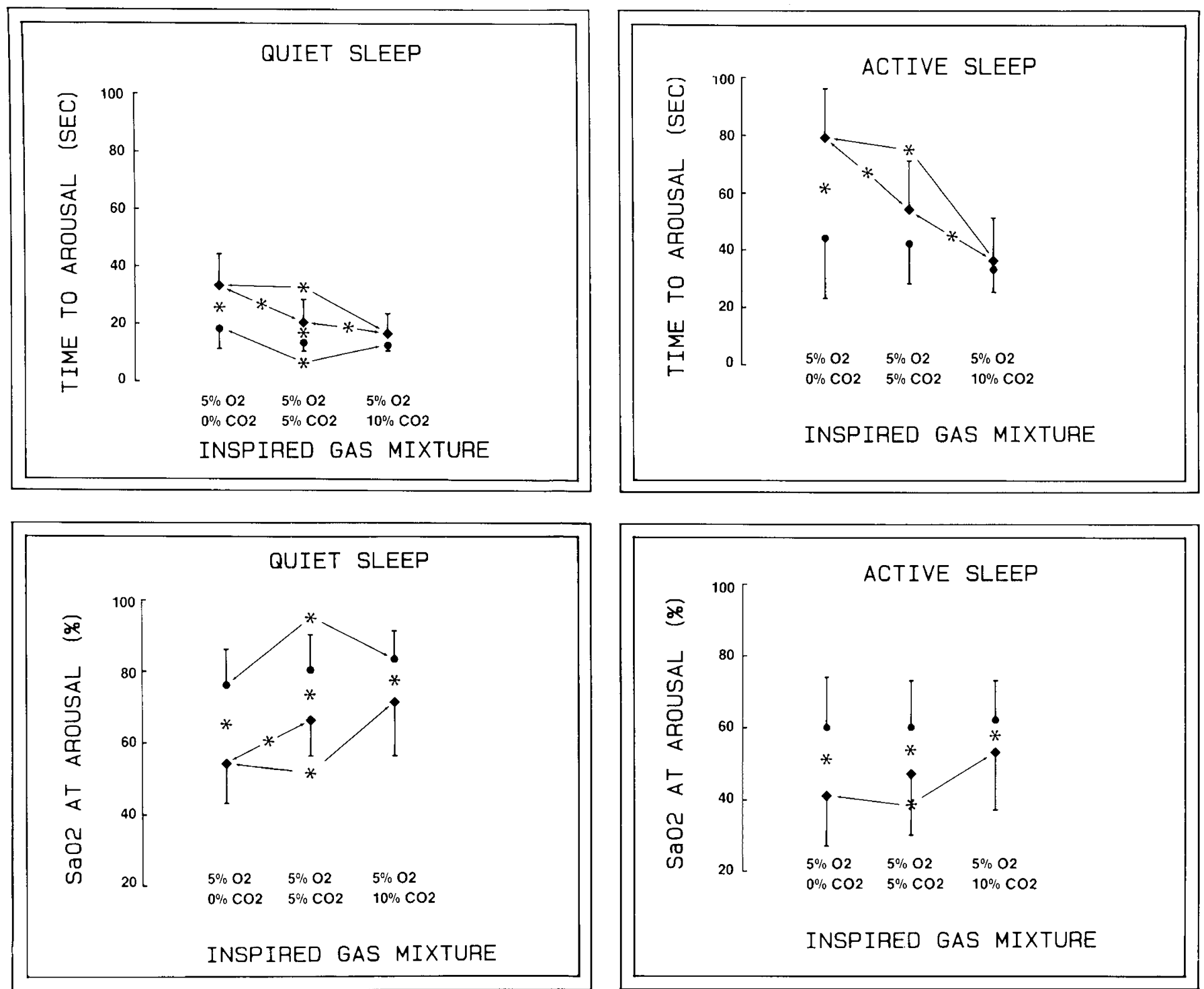

Fig. 2. Graphs showing time to arousal and arterial $\mathrm{Hb}$ oxygen saturation $\left(\mathrm{SaO}_{2}\right)$ at arousal when the lambs breathed either $5 \% \mathrm{O}_{2}-0 \% \mathrm{CO}_{2}, 5 \%$ $\mathrm{O}_{2}-5 \% \mathrm{CO}_{2}$, or $5 \% \mathrm{O}_{2}-10 \% \mathrm{CO}_{2}$ during quiet sleep and active sleep. Data are means $\pm 1 \mathrm{SD}$. Group $\mathrm{N}(\bullet)$ was studied without prior exposure to rapidly developing hypoxemia and group $\mathrm{H}(\diamond)$ was studied after exposure to rapidly developing hypoxemia for 100 epochs of sleep until they aroused. ${ }^{*} p<0.05$ as determined by the Duncan's multiple range test. During quiet sleep, there was a significant group $(p=0.021)$, period $(p=$ $0.055)$ and gas $(p=0.000)$ effect on the $\mathrm{SaO}_{2}$ at arousal and a significant group $(p=0.014)$ and gas $(p=0.000)$ effect on the time to arousal as determined by the analysis of variance. During active sleep, there was a significant group $(p=0.097)$, period $(p=0.000)$, and gas $(p=0.005)$ effect on the $\mathrm{SaO}_{2}$ at arousal and a significant group $(p=0.046)$ and gas $(p=0.000)$ effect on the time to arousal as determined by the analysis of variance.

during inhalation of $5 \%$ oxygen or during inhalation of $10 \%$ carbon dioxide. Blood pressure increased more during inhalation of $5 \%$ oxygen (quiet sleep $91 \pm 10 / 61 \pm 8$ to $96 \pm 14 / 67 \pm 12$, active sleep $84 \pm 8 / 54 \pm 8$ to $103 \pm 13 / 66 \pm 13$ ) than during inhalation of $10 \%$ carbon dioxide (quiet sleep $88 \pm 3 / 60 \pm 5$ to $90 \pm 4 / 62 \pm 5$, active sleep $82 \pm 11 / 54 \pm 11$ to $86 \pm 9 / 57 \pm 8$ ). We are currently conducting experiments to determine the mechanism(s) of the arousal response during alveolar hypoxia and during alveolar hypercarbia.

Repeated exposure to rapidly developing hypoxemia did influence the arousal response in both quiet sleep and active sleep. The time to arousal was increased and the saturation at arousal was decreased after repeated exposure to rapidly developing hypoxemia (Fig. 2). Although it has been known for some time that the arousal response from sleep habituates to some environmental stimuli [e.g. acoustic (18)], we are unaware of other investigators who have provided direct evidence that the arousal response to respiratory stimuli changes after repeated exposure to the stimulus. We have previously shown that the arousal response from sleep changes after repeated exposure to upper airway obstruction during active sleep but not quiet sleep in lambs (19). Inasmuch as the arousal response to upper airway obstruction appears to be primarily mediated by rapidly developing hypoxemia in active sleep and, perhaps by lung or chest wall mechanoreceptors during quiet sleep $(20,21)$, it appears that the response decrement occurs in response to some stimuli (e.g., hypoxemia) but not to others (e.g., mechanoreceptors) and is not sleep state dependent. We do not believe that the arousal response decrement after repeated exposure to rapidly developing hypoxemia or to repeated exposure to upper airway obstruction is due to sleep fragmentation per se, as sleep fragmentation, produced by intense auditory stimuli over a 36- to 42-h time period, does not significantly affect the arousal response from quiet sleep or active sleep to upper airway obstruction in lambs (11). In addition, the arousal response decrement does not appear to be mediated by endogenous opiates as it is not altered by naloxone (22).

In lambs previously exposed to rapidly developing hypoxemia, 
Table 1. Blood pressure response to alveolar hypoxia with differing levels of inspired carbon dioxide in both groups of lambs during sleep*

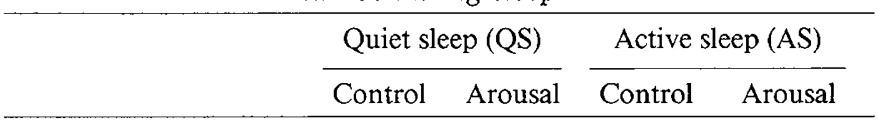

Systolic blood pressure $(\mathrm{mm} \mathrm{Hg})$

[QS: G 0,714, M 0.040, P 0.117]

[AS: G 0.854, M 0.035, P 0.094]

$\begin{array}{llllr}\text { Group N } & & & \\ 5 \% \mathrm{O}_{2}-0 \% \mathrm{CO}_{2} & 91 \pm 10 & 96 \pm 14 & 84 \pm 8 \dagger & 103 \pm 13 \\ 5 \% \mathrm{O}_{2}-5 \% \mathrm{CO}_{2} & 91 \pm 13 & 98 \pm 15 & 82 \pm 9 \dagger & 99 \pm 14 \\ 5 \% \mathrm{O}_{2}-10 \% \mathrm{CO}_{2} & 86 \pm 9 & 91 \pm 13 & 83 \pm 12 \dagger & 100 \pm 15 \\ & & & & \\ \text { Group } \mathrm{H} & & & & \\ 5 \% \mathrm{O}_{2}-0 \% \mathrm{CO}_{2} & 87 \pm 11 \dagger & 99 \pm 17 & 80 \pm 9 \dagger & 107 \pm 11 \\ 5 \% \mathrm{O}_{2}-5 \% \mathrm{CO}_{2} & 87 \pm 14 & 93 \pm 18 & 79 \pm 12 \dagger & 102 \pm 14 \\ 5 \% \mathrm{O}_{2}-10 \% \mathrm{CO}_{2} & 81 \pm 14 & 87 \pm 18 & 80 \pm 18 \dagger & 96 \pm 13\end{array}$

Diastolic blood pressure ( $\mathrm{mm} \mathrm{Hg}$ )

[QS: G 0.775, M 0.115, P 0.582]

[AS: G $0.689, \mathrm{M} 0.351, \mathrm{P} 0.066$ ]

Group N

$\begin{array}{lllll}5 \% \mathrm{O}_{2}-0 \% \mathrm{CO}_{2} & 61 \pm 8 & 67 \pm 12 & 54 \pm 8 \dagger & 66 \pm 13 \\ 5 \% \mathrm{O}_{2}-5 \% \mathrm{CO}_{2} & 61 \pm 11 \dagger & 69 \pm 14 & 53 \pm 8 \dagger & 64 \pm 10 \\ 5 \% \mathrm{O}_{2}-10 \% \mathrm{CO}_{2} & 58 \pm 10 \dagger & 66 \pm 13 & 53 \pm 11 \dagger & 66 \pm 13\end{array}$

Group $\mathrm{H}$

$\begin{array}{lllll}5 \% \mathrm{O}_{2}-0 \% \mathrm{CO}_{2} & 63 \pm 4 \dagger & 73 \pm 10 & 56 \pm 7 \dagger & 67 \pm 6 \\ 5 \% \mathrm{O}_{2}-5 \% \mathrm{CO}_{2} & 64 \pm 8 & 69 \pm 11 & 57 \pm 5 & 66 \pm 9 \\ 5 \% \mathrm{O}_{2}-10 \% \mathrm{CO}_{2} & 59 \pm 5 & 64 \pm 8 & 57 \pm 10 & 63 \pm 8\end{array}$

* Values are means $\pm 1 \mathrm{SD}$ for $n=7$ in group $\mathrm{N}$ and $n=5$ in group $\mathrm{H}$. Probability of differences by multivariate analyses of variance is indicated as follows: group $(G)$, gas mixture $(M)$, period $(P)$.

$\dagger$ Significant differences $(p<0.05)$ between control and arousal values by Duncan's multiple range test.

Table 2. Heart rate response to alveolar hypoxia with differing levels of inspired carbon dioxide in both groups of lambs during sleep*

\begin{tabular}{cccc}
\hline Quiet sleep (QS) & & Active sleep (AS) \\
\cline { 2 - 3 } \cline { 5 - 6 } & Control Arousal & & Control Arousal \\
\hline
\end{tabular}

Heart rate $(\mathrm{bpm})$

[QS: G 0.723, M 0.018, P 0.742]

[AS: G 0.279, M 0.144, P 0.016]

Group N

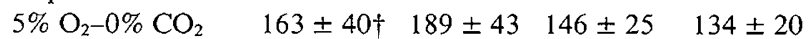

$\begin{array}{lllll}5 \% \mathrm{O}_{2}-5 \% \mathrm{CO}_{2} & 157 \pm 30 & 175 \pm 35 & 149 \pm 21 & 128 \pm 22\end{array}$

$5 \% \mathrm{O}_{2}-10 \% \mathrm{CO}_{2} \quad 164 \pm 42 \quad 180 \pm 36 \quad 143 \pm 24 \quad 121 \pm 21$

Group $\mathrm{H}$

$5 \% \mathrm{O}_{2}-0 \% \mathrm{CO}_{2} \quad 170 \pm 12 \quad 193 \pm 19 \quad 156 \pm 18 \quad 142 \pm 30$

$5 \% \mathrm{O}_{2}-5 \% \mathrm{CO}_{2} \quad 179 \pm 11 \quad 184 \pm 15 \quad 163 \pm 18 \quad 140 \pm 34$

$5 \% \mathrm{O}_{2}-10 \% \mathrm{CO}_{2} \quad 172 \pm 17 \quad 168 \pm 13 \quad 166 \pm 15 \dagger \quad 125 \pm 13$

* Values are means $\pm 1 \mathrm{SD}$ for $n=7$ in group $\mathrm{N}$ and $n=5$ in group

$\mathrm{H}$. Probability of differences by MANOVA is indicated as follows: group $(\mathrm{G})$, gas mixture $(\mathrm{M})$, period $(\mathrm{P})$.

$\dagger$ Significant differences $(p<0.05)$ between control and arousal values by Duncan's multiple range test.

there was evidence for an interaction between oxygen and carbon dioxide in initiating arousal from both quiet sleep and active sleep (Fig. 2). Thus, our results extend those of Phillipson et al. (15) as we have provided evidence that once the arousal response adapts to one stimulus (i.e. oxygen), another may take the dominant role in initiating arousal (i.e. carbon dioxide). It is
Table 3. Respiratory frequency response to alveolar hypoxia with differing levels of inspired carbon dioxide in both groups of lambs during sleep

$\frac{\text { Quiet sleep (QS) }}{\text { Control Arousal }} \quad \frac{\text { Active sleep (AS) }}{\text { Control Arousal }}$

Respiratory rate (breaths/min)

[QS: G 0.441, M 0.646, P 0.003]

[AS: G $0.657, \mathrm{M} 0.763, \mathrm{P} 0.005$ ]

Group N

$5 \% \mathrm{O}_{2}-0 \% \mathrm{CO}_{2} \quad 30 \pm 8 \dagger \quad 42 \pm 11 \quad 36 \pm 6 \dagger \quad 50 \pm 3$

$5 \% \mathrm{O}_{2}-5 \% \mathrm{CO}_{2} \quad 29 \pm 7 \dagger \quad 44 \pm 14 \quad 39 \pm 7 \dagger \quad 53 \pm 8$

$5 \% \mathrm{O}_{2}-10 \% \mathrm{CO}_{2} \quad 29 \pm 9 \dagger \quad 46 \pm 14 \quad 35 \pm 7 \dagger \quad 50 \pm 6$

Group $\mathrm{H}$

$5 \% \mathrm{O}_{2}-0 \% \mathrm{CO}_{2} \quad 30 \pm 4 \dagger \quad 56 \pm 8 \ddagger \quad 35 \pm 7 \dagger \quad 53 \pm 9$

$5 \% \mathrm{O}_{2}-5 \% \mathrm{CO}_{2} \quad 29 \pm 4 \dagger \quad 53 \pm 2 \ddagger \quad 36 \pm 3 \dagger \quad 57 \pm 12$

$5 \% \mathrm{O}_{2}-10 \% \mathrm{CO}_{2} \quad 30 \pm 2 \dagger \quad 47 \pm 7 \quad 37 \pm 8 \dagger \quad 53 \pm 9$

* Values are means $\pm 1 \mathrm{SD}$ for $n=7$ in group $\mathrm{N}$ and $n=4$ in group $\mathrm{H}$. Probability of differences by MANOVA is indicated as follows: group $(\mathrm{G})$, gas mixture $(\mathrm{M})$, period $(\mathrm{P})$.

$\dagger$ Significant differences $(p<0.05)$ between control and arousal values by Duncan's multiple range test are indicated.

$\ddagger$ Significant differences between group $\mathrm{N}$ and group $\mathrm{H}$ for a given gas mixture.

Table 4. Diaphragm electromyographic response to alveolar hypoxia with differing levels of inspired carbon dioxide in both groups of lambs during sleep*

\begin{tabular}{|c|c|c|}
\hline & Quiet Sleep (QS) & Active Sleep (AS) \\
\hline \multicolumn{3}{|c|}{$\begin{array}{l}\text { Diaphragm electromyographic activity (\% change from control befor } \\
\text { arousal) }\end{array}$} \\
\hline \multicolumn{3}{|c|}{ [QS: G 0.469, M 0.248] [AS: G 0.245, M 0.036] } \\
\hline \multicolumn{3}{|l|}{ Group N } \\
\hline $5 \% \mathrm{O}_{2}-0 \% \mathrm{CO}_{2}$ & $85 \pm 36$ & $48 \pm 26$ \\
\hline $5 \% \mathrm{O}_{2}-5 \% \mathrm{CO}_{2}$ & $91 \pm 61$ & $68 \pm 54$ \\
\hline $5 \% \mathrm{O}_{2}-10 \% \mathrm{CO}_{2}$ & $73 \pm 50$ & $97 \pm 51$ \\
\hline \multicolumn{3}{|l|}{ Group H } \\
\hline $5 \% \mathrm{O}_{2}-0 \% \mathrm{CO}_{2}$ & $104 \pm 81$ & $88 \pm 32$ \\
\hline $5 \% \mathrm{O}_{2}-5 \% \mathrm{CO}_{2}$ & $133 \pm 57$ & $95 \pm 47$ \\
\hline $5 \% \mathrm{O}_{2}-10 \% \mathrm{CO}_{2}$ & $85 \pm 84$ & $118 \pm 48$ \\
\hline
\end{tabular}

* Values are means \pm 1 SD for $n=7$ in group $\mathrm{N}$ and $n=4$ in group $\mathrm{H}$. Probability of differences by MANOVA is indicated as follows: group $(\mathrm{G})$, gas mixture $(\mathrm{M})$.

likely that our results have implications for the arousal response to apnea, both central and obstruction, during the first few days of postnatal life and also in infants who have been exposed to intermittent or chronic hypoxemia but who are not in ventilatory failure.

We have previously reported that sleep state does not affect the cardiovascular response to alveolar hypoxia (23). In these experiments, seven lambs were exposed to $10 \%$ oxygen during several epochs of quiet sleep and active sleep; this produced an increase in heart rate and no significant change in mean systemic blood pressure. However, in our study, exposure to $5 \%$ oxygen produced an increase in heart rate during quiet sleep and tended to decrease heart rate during active sleep; blood pressure, both systolic and diastolic, tended to increase during both sleep states. From studies on anesthetized adult and newborn animals it has been suggested that the primary cardiovascular response to carotid chemoreceptor stimulation is one of bradycardia and systemic vasoconstriction $(24,25)$. However, carotid chemoreceptor stimulation also increases respiration and this produces secondary changes that consist of tachycardia and systemic vasodilation. We did observe an increase in respiratory rate and diaphragm 
electrical activity during rapidly developing hypoxemia in both sleep states (Table 3 and 4). We would speculate that the heart rate response during alveolar hypoxia depends not only on the influence of sleep state on the processing of information from the periphery, but also on the degree of stimulation peripheral receptors (e.g. chemoreceptors, mechanoreceptors). During quiet sleep, it would appear that information from the periphery during alveolar hypoxia, both 5 and $10 \%$ oxygen, is processed such that pulmonary stretch receptor activity dominates peripheral chemoreceptor activity and the secondary response of tachycardia is observed. During active sleep, it would appear that information from the periphery is processed during inhalation of $5 \%$ oxygen such that activity from the chemoreceptors prevails and a primary response of bradycardia is observed; whereas, during inhalation of $10 \%$ oxygen information from the periphery is processed such that activity from the lung stretch receptors prevails and a secondary response of tachycardia is observed.

The arousal response from sleep has been suggested to be an important protective response that may prevent severe hypoxemia and death during an apneic episode (26). Two recent studies have provided evidence of an abnormal arousal response from quiet sleep during hypoxemia in infants who have had an ALTE. McCulloch et al. (27) found that only one of 11 ALTE infants aroused in response to progressive alveolar hypoxia $\left(\mathrm{FIO}_{2} 0.15\right)$ compared to 14 of 22 normal infants. After this study, it was suggested that the lack of an arousal response in $30 \%$ of the control infants was due to lack of maximal chemoreceptor stimulation (28). Subsequently, van der Hal et al. (28) found that nine of nine control infants aroused in response to more pronounced alveolar hypoxia $\left(\mathrm{FIO}_{2} 0.11\right)$ compared to only 19 of 50 ALTE infants. It is particularly interesting, that although a large percentage of the ALTE infants did not arouse in response to hypoxemia, almost all aroused in response to hypercapnia. McCulloch et al. (27) found that 10 of 11 ALTE infants aroused in response to hypercapnia compared to 19 of 19 control infants and van der Hal et al. (28) found that 52 of 52 ALTE infants aroused in response to hypercapnia compared to seven of seven control infants.

Is it possible that these ALTE infants had an impaired arousal response to hypoxemia because they had been repeatedly exposed to rapidly developing hypoxemia during periods of apnea? Data from group $\mathrm{H}$ in the present study provide evidence that an arousal response decrement can develop after repeated exposure to rapidly developing hypoxemia. Furthermore, our data also provide evidence that a greater interaction exists between oxygen and carbon dioxide in causing arousal from sleep after the development of an arousal response decrement to hypoxemia alone. Experiments are currently being conducted to determine whether an arousal response decrement develops after repeated exposure to hypercapnia alone.

\section{REFERENCES}

1. Muller NL, Francis PW, Gurwitz D, Levison H, Bryan AC 1980 Mechanism of hemoglobin desaturation during rapid-eye-movement sleep in normal subjects and in patients with cystic fibrosis. Am Rev Respir Dis 121:463469
2. Taussig LM Long-term management and pulmonary prognosis in bronchopulmonary dysplasia. In: Farrell PM, Taussig LM (eds) Bronchopulmonary Dysplasia and Related Chronic Disorders. Ross Laboratories, Columbus, $\mathrm{OH}, \mathrm{pp}$ 126-135

3. Hudgel DW, Kellum R, Martin RJ, Johnson B 1982 Depressed arousal response to airflow obstruction-a possible factor in near fatal nocturnal asthma. Am Rev Respir Dis 125:202

4. Henderson-Smart DJ, Read DJC 1979 Ventilatory responses to hypoxemia during sleep in the newborn. J Dev Physiol 1:195-208

5. Jeffery HE, Read DJC 1980 Ventilatory responses of newborn calves to progressive hypoxia in quiet and active sleep. J Appl Physiol 48:892-895

6. Gastaut H, Tassinari CA, Duron B 1966 Polygraphic study of the episodic diurnal and nocturnal (hypnic and respiratory) manifestations of the Pickwickian syndrome. Brain Res 2:167-186

7. Walsh RE, Michealson ED, Harkerload LE, Zichelboim A, Sackner MA 1972 Upper airway obstruction in obese patients with sleep disturbances and somnolence. Ann Intern Med 76:185-192

8. Remmers JE, DeGroot WJ, Sauerland EK, Anch AM 1978 Pathogenesis of upper airway occlusion during sieep. J Appl Physiol 44:931-938

9. Frank Y, Kravath RE, Pollak CP, Weitzman ED 1983 Obstructive sleep apnea and its therapy: clinical and polysomnographic manifestations. Pediatrics 71:737-740

10. Stark AR, Thach BT 1981 Recovery of airway patency after obstruction in normal infants. Am Rev Respir Dis 123:691-693

11. Fewell JE 1987 Influence of short-term sleep fragmentation produced by intense auditory stimuli on the arousal response to upper airway obstruction in lambs. J Dev Physiol 9:409-417

12. Fewell JE, Baker SB 1987 Arousal from sleep during rapidly developing hypoxemia in lambs. Pediatr Res 22:471-477

13. Winer BJ 1971 Single-factor experiments having repeated measures on the same elements. In: Statistical Principles in Experimental Design. McGrawHill Book Company, New York, pp 261-308

14. Zar JH 1979 Multiple comparisons. In: Biostistical Analyses. Prentice-Hall, Englewood Cliffs, NJ, pp 151-162

15. Phillipson EA, Sullivan CE, Read DJC, Murphy E, Kozar LF 1978 Ventilatory and waking responses to hypoxia in sleeping dogs. J Appl Physiol 44:512520

16. Baker SB, Fewell JE 1988 Arousal and cardiopulmonary response to normoxemic hypercapnia in lambs. J Dev Physiol (in press)

17. Fewell JE, Johnson P 1984 Acute increases in blood pressure cause arousal from sleep in lambs. Brain Res 311:259-265

18. Sharpless S, Jasper H 1956 Habituation of the arousal reaction. Brain 79:655680

19. Fewell JE, Williams BJ, Szabo JS, Taylor BJ 1988 Influence of repeated upper airway obstruction on the arousal and cardiopulmonary response to upper airway obstruction in lambs. Pediatr Res 23:191-195

20. Fewell JE 1985 Arousal and cardiorespiratory responses to upper airway obstruction during sleep in lambs. In: Jones CT, Nathanielsz PW (eds) The Physiological Development of the Fetus and Newborn. Academic Press, London, pp 217-222

21. Baker SB, Fewell JE 1987 Effect of hyperoxia on the arousal response to upper airway obstruction. Pediatr Res 21:116-120

22. Konduri GK, Fewell JE 1987 Do endogenous opiates cause habituation of the arousal from sleep to hypoxemia in lambs? Clin Res (in press)

23. Fewell JE, Williams BJ, Hill DE 1984 Sleep does not affect the cardiovascular response to alveolar hypoxia in lambs. J Dev Physiol 6:401-405

24. Daly M de B 1972 Interaction of cardiovascular reflexes. In: Gilliland J, Francis $\mathrm{J}$ (eds). Lectures on the Scientific Basis of Medicine. The Athlone Press, University of London, London, England, pp 307-332

25. Fewell JE, Ramick RA, Taylor BJ 1986 Influence of the ventilatory response on the cardiovascular response to hypoxemia in lambs. Pediatr Res 20:368A(abstr)

26. Phillipson EA, Sullivan CE 1978 Arousal: the forgotten response to respiratory stimuli. Am Rev Respir Dis 118:807-809

27. McCulloch K, Brouillette RT, Guzzetta AJ, Hunt CE 1982 Arousal responses in near-miss sudden infant death syndrome and in normal infants. J Pediatr 101:911-917

28. van der Hal AL, Rodriguez AM, Sargent CW, Platzker ACG, Keens TG 1985 Hypoxic and hypercapneic arousal responses and prediction of subsequent apnea in infancy. Pediatrics 75:848-854 